\title{
Evaluation of Serum Level of Netrin 1 in Patients with Psoriasis vulgaris \\ H.H.Sabry ${ }^{1}$, N.A.Abdelhafeez ${ }^{2}$, E.M.El-Sayed ${ }^{1}$ and E.H.Ragheb ${ }^{1}$ \\ ${ }^{1}$ Dermatology Venereology and Andrology, Dept., Faculty of Medicine, Benha Univ., Benha, Egypt \\ ${ }^{2}$ Clinical and Chemical Pathology, Dept., Faculty of Medicine, Benha Univ., Benha, Egypt \\ E-Mail: dr.eman helal85@gmail.com
}

\begin{abstract}
The etiology of psoriasis stays indistinct, in spite of the fact that there is proof for hereditary inclination. The part of the resistant framework in psoriasis causation is likewise a significant subject of examination. The point of the current investigation was to assess serum levels of netrin 1 protein in patients with psoriasis and it's relationship with sickness seriousness Patient and strategies: A cross area case control study was led on ninety subjects ordered into two gatherings: Patient gathering: Sixty patients grumbling of psoriasis vulgaris. Control gathering: Thirty clear solid age and sex coordinated with individual. Psoriasis seriousness was assessed by PASI score. All read subjects were tried for Serum level of nertin 1 by compound connected immunosorbent measure (ELISA). Results: There was high critical negative relationship between's Netrin1 level and degree additionally there was huge negative connection between's Netrin1and Disease term while there was no huge connection between's Netrin 1 and age and sex Conclusion: There is a job of Nerrin1 in the pathogenesis of psoriasis.Netrin1 can be utilized as pointer of sickness degree and infection length.
\end{abstract}

Keywords: Netrin 1, Psoriasis vulgaris, Psoriasis areas and severity index.

\section{Introduction}

Psoriasis is a chronc, resistant - interceded fundamental sickness related with huge dismalness and debilitated personal satisfaction [1]. The revealed pervasiveness of psoriasis in nations ranges somewhere in the range of $0.09 \%$ and $11.4 \%$ making psoriasis a genuine worldwide issue [2].

Psoriasis is a multisystem illness predominately showed as persistent aggravation of the skin and described by flaky, erythematous patches, papules, and plaques, which are regularly pruritic [3]. Somewhere in the range of $1.3 \%$ and $34.7 \%$ of people with psoriasis create persistent, provocative joint inflammation (psoriatic joint pain) that prompts joint distortions and inability [4]. People with psoriasis are accounted for to be at expanded danger of creating other genuine clinical conditions like cardiovascular and other no communicable sicknesses [5].

The etiology of psoriasis stays indistinct, in spite of the fact that there is proof for hereditary inclination [6]. The part of the invulnerable framework in psoriasis causation is likewise a significant subject of examination. In spite of the fact that there is an idea that psoriasis could be an immune system sickness, no auto antigen that could be mindful has been characterized at this point. Psoriasis can likewise be incited by outer and inward triggers, including gentle injury, burn from the sun, contaminations, foundational medications and stress [7]. Netrins are a class of proteins engaged with axon direction. They are named after the Sanskrit word "netr", which signifies "one who guides [8].

Netrin-1 (NTN1) is a protein that in people is encoded by the NTN1 quality. Netrin is remembered for a group of laminin-related discharged proteins. The capacity of this quality has not yet been characterized; nonetheless, netrin is believed to be associated with axon direction and cell movement during improvement. Transformations and loss of articulation of netrin propose that variety in netrin might be associated with malignancy improvement [9].
Vascular endothelial cells play basic obstruction for leukocyte actuation and movement into organs by creating repellent elements to leukocytes, for example, netrin-1. Movement of fiery cells to the site of injury is a basic cell reaction to start the expulsion of dead cells and initiate a recovery reaction, down regulation of these chemo repellent factors, for example, netrin-1 during organ injury may compound aggravation [10)].

The point of the current investigation was to assess serum levels of netrin 1 protein in patients with psoriasis and it's connection with sickness seriousness.

\section{Patient and method}

A cross area case control study was directed on ninety subjects arranged into two gatherings: Patient gathering: Sixty patients griping of psoriasis vulgaris. Control gathering: Thirty clear sound age and sex coordinated with individual .

Patients had been selected from Outpatient Clinic of Dermatology, Andrology and Venerology, Benha University Hospitals from Octobre 2019 to January 2020.Clinical evaluation was done in Dermatology, Andrology and Venerology Department. Serological evaluation was done in Clinical Pathology Department.

\subsection{Inclusion criteria}

- Patients(male and female) suffered from psoriasis vulgaris.

- Ages were between 16 and 35 years.

- $\quad$ PASI score $>12$ (modetete and severe )(8).

- Patients stopped treatment one month before beginning of the procedure.

2.2 Exclusion criteria

- Patient with other autoimmune or allergic diseases.

- Patients with renal or hepatic disease.

- Patient recieving oral immunosuppressive treatment within 6 weaks from sampling

- Patient recieving topical immunosuppressive treatment within 2 weaks from sampling. 
Psoriasis severity was evaluated by PASI score: Psoriasis areas and severity index (PASI) score denotes an objective method of scoring severity of psoriasis, reflecting not only the body surface area but also erythema, induration and scaling [11].

Psoriasis territories and seriousness list score goes from 0 to 72 and it joins the appraisal of four body regions: head and neck, upper appendages, trunk and lower appendages. To survey influenced body surface zone, the extent of skin influenced in every region is given by a mathematical score, addressing the extent in question. Inside every zone the seriousness of the injuries is surveyed by three signs, erythema, thickness/induration, and desquamation/scaling; every one of the three signs is evaluated on a five-point scale. At last, the PASI score is determined by a suitable recipe.

All read subjects were tried for Serum level of nertin 1 by catalyst connected immunosorbent measure (ELISA). This test was finished utilizing Human Netrin1ELISA Kit given by Bioassay Technology Laboratory China

The clinical information were recorded on a report structure. These information were classified and dissected utilizing the PC program SPSS (Statistical bundle for sociology) variant 20 to acquire.

\section{Results}

The current study included sixty psoriatic patients;34 males $56.7 \%$ and 26 females $43.3 \%$. Their ages ranges from 18-42 years with a mean age of $38.8+4.97$.Thirty clinically free individuals served as a control group ;15 males (50\%) and 15 females 50\%.Their ages ranged from 20-41 years with a mean age of 42.23 \pm 9.91 .

By comparison between the two groups ,there was no statistically significant difference regarding Age $(\mathrm{p}<0.77)$ and sex $(\mathrm{p}=0.55)$ Table $(1)$.

Results of this study showed a family history in $10 \%$ of cases, joint manifestation in $20 \%$ of cases, recurrences were reported in $93.3 \%$ of cases.Psoriasis was with acute onset in $10 \%$ and with chronic onset in $90 \%$ of patients. Psoriasis severity was moderate in $40 \%$, and severe in $60 \%$ of patients. Patients used topical treatment in $70 \%$, methotrexate in $13.3 \%$ and narrow band in $16.7 \%$ of cases Table (2).

Patients were classified according to PASI score to moderate and severe degree. PASI score was $27.63 \pm 5.81$ in severe degree $16.95 \pm 2.17$ in moderate degree.
There were statically significant difference between moderate and severe degree of psoriasis as regard age $(\mathrm{p}=0.012)$, recurrence $(\mathrm{p}=0.022)$ and previous treatment $(\mathrm{p}=0.031)$, while there were no statically significant difference as regard race $(\mathrm{p}=0.06)$, family history $(\mathrm{p}=1.0)$, joint manifestation $(p=0.75)$, onset of disease $(p=0.21)$ and duration $(\mathrm{p}=0.18)$.

Results of this study showed a significant degree between PASI score and patients with joint manifestations $(\mathrm{p}=0.019)$, and high significant degree with disease severity $(p<0.001)$, while there were no significant degree between PASI score and race $(\mathrm{p}=0.31)$, family history $(\mathrm{p}=0.096)$, onset of disease $(\mathrm{p}=0.15)$ or previous treatment $(\mathrm{p}=0.87)$.

The mean serum Netrin1 levels were statically significantly lower in psoriatic patients $74.01 \pm 34.91$ than control group 248.74 \pm 360.07 ( $\mathrm{p}<0.001)$.

Mean serum Netrin 1 levels in females were higher than males with statically significant value $(\mathrm{p}=0.015)$.

Mean serum Netrin 1 level in patients with +ve family history lower than patients with -ve family history with non significant value $(\mathrm{p}=0.22)$.

Mean serum Netrin 1 level in patients with +ve joint manifestation lower than patients with - ve joint manifestation with non significant value $(\mathrm{p}=0.08)$.

Mean serum Netrin 1 level in patients with +ve recurrence was lower than patients with -ve recurrence with high significant value $(\mathrm{p}=0.001)$.

Mean serum Netrin 1 level in patients had acute disease was higher than patients had chronic disease with significant value $(\mathrm{p}=0.002)$.

ROC curve analysis showed that a serum level of netrin1 is $88.3 \mathrm{pg} / \mathrm{ml}$.It is decreased in patients with psoriasis. Sensitivity of Netrin 1 was $70 \%$, Specificity was $56.7 \%$, PPV was $76.4 \%$, NPV was $48.6 \%$, and Accuracy was $65.6 \%$.

There were no statically significant correlation between PASI score and disease duration $(\mathrm{p}=0.13)$ or age $(\mathrm{p}=0.08)$.

This study showed that that there were high statically significant negative correlation between netrin1 and severity $(\mathrm{p}<0.001)$; also there were significant negative correlation between netrin1 and Disease duration $(\mathrm{p}=0.04)$ while there were no significant correlation between netrin 1 and age $(\mathrm{p}=0.21)$.

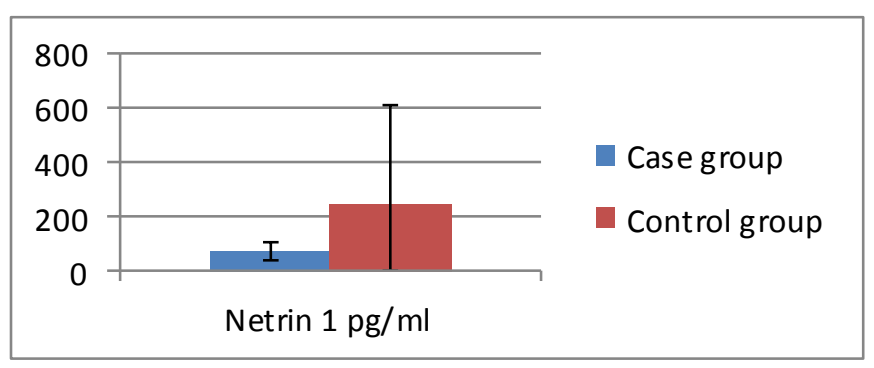

Fig (1) Netrin 1 pg/ml level in patients and control. 


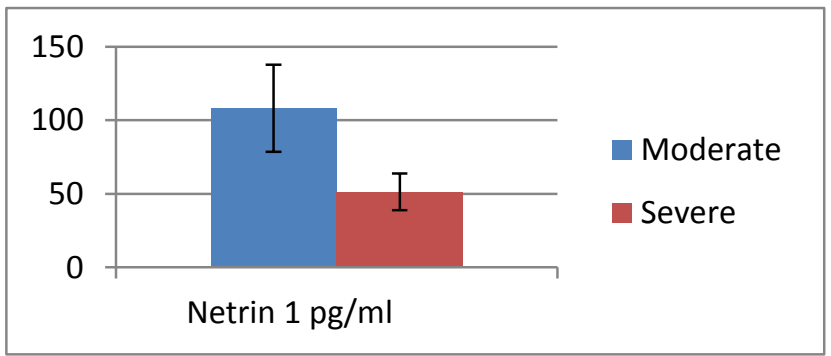

Fig (2) Comparison between moderate and severe degree according to Netrin 1

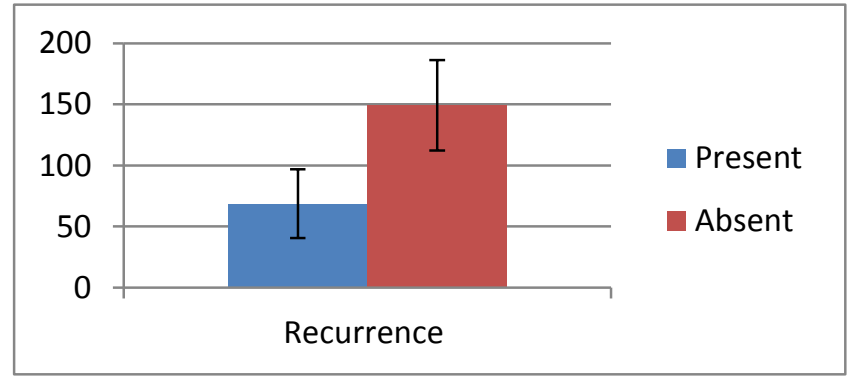

Fig (3) Relation between Netrin 1 and recurrence.

Table (1) Validity of netrin1 in prediction of cases.

\begin{tabular}{|c|c|c|c|c|c|c|}
\hline \multirow{2}{*}{ Netrin 1 pg/ml } & \multicolumn{2}{|c|}{ Case group (60) } & \multicolumn{2}{|c|}{ Control group (30) } & \multirow{2}{*}{$\begin{array}{c}\text { Statistical } \\
\text { test }\left(\mathrm{x}^{2}\right)\end{array}$} & \multirow{2}{*}{$P$ value } \\
\hline & No & $\%$ & No & $\%$ & & \\
\hline$\leq 88.3$ & 42 & 70.0 & 13 & 43.3 & 5.98 & $0.014 *$ \\
\hline$>88.3$ & 18 & 30.0 & 17 & 56.7 & & \\
\hline $\operatorname{AUC}(95 \% \mathrm{CI})$ & & & 0.707 & $8-0.825)$ & & \\
\hline Cut-off point & & & & & & \\
\hline Sensitivity & & & & & & \\
\hline Specificity & & & & & & \\
\hline PPV & & & & & & \\
\hline NPV & & & & & & \\
\hline Accuracy & & & & & & \\
\hline
\end{tabular}

\section{Discussion}

The cooperation of netrin-1/receptors and, all the more explicitly, netrin-1/UNC5H2, was as of late demonstrated to be associated with the morphogenesis of endothelial vessels. To be sure, despite the fact that it is obviously shown that UNC5H2 communicated by the tip cells is a central member in formative angiogenesis [12].

The point of this investigation was to assess the conceivable job of Netrin 1 in pathogenesis of psoriasis by estimating its level in the serum of patients and its relationship with illness seriousness.

The current investigation was directed more than 90 members, 60 psoraitic patients and 30 controls, with mean period of $33.28 \pm 9.43$ and mean Netrin of $132.25 \pm 223.42$ $\mathrm{pg} / \mathrm{ml}$ ).

In this investigation guys are influenced than females that guys addresses $54.4 \%$ and females $45.6 \%$ of the considered populace.

This was against what expressed by [13] who announced that Psoriasis has been considered to influence the two sexual orientations similarly.
The current examination expressed that family ancestry was positive in $90 \%$ of cases, Joint appearance were available in $20 \%$ of cases, Recurrence was available in $93.3 \%$, Type was intense in $10 \%$ and constant in $90 \%$, degree moderate in $40 \%$, and serious in $60 \%$, history of past therapy was neighborhood in $70 \%$, MTX in $13.3 \%$ and Narrow band in $16.7 \%$.

Solmazet al. [14] confirmed that in contrast with patients with no family ancestry, having a relative with psoriasis stayed a danger factor for enthesitis and more youthful beginning of psoriasis, having a relative with PsA was a danger factor for presence of disfigurements and defensive against having plaque type psoriasis, this discoveries support the part of family ancestry in pathogenesis of psoriasis.

In this investigation we announced that there was critical distinction between the cases and controls as respect Netrin 1 level lower level of Netrin lin cases gathering, while there is no huge contrast between the examined bunches as respect sex and age. 
This was in concurrence with what expressed by Demir et al. [15] who announced that patients with psoriasis were appeared to have essentially lower levels of netrin-1 than solid controls.

The intricate connection between the insusceptible framework and skin cells causes persistent aggravation of the skin [16].

In our examination we announced that ROC bend investigation shows that at acut off mark of $88.3 \mathrm{pg} / \mathrm{ml}$ Sensitivity of Netrin 1 was $70 \%$, Specificity was $56.7 \%$, PPV was $76.4 \%$, NPV was $48.6 \%$, Accuracy was $65.6 \%$.

Wilson and his associates in 2006 [17] have performed transitory measures utilizing angle dosages of netrin-1, and noticed a maximal action at $50 \mathrm{ng} / \mathrm{ml}$. Unexpectedly, there was no critical expansion in endothelial cell movement for netrin-1 fixation better than $1 \mathrm{ng} / \mathrm{ml}$. Curiously, this is the negligible portion utilized in measures performed by $\mathrm{Lu}$ et al. [18] implying that at high dosages netrin-1 could lose its capacity to actuate endothelial cells relocation and even forestalls endothelial cells development.

In this investigation we showed that there was high critical connection between's PASI score and degree, while there is no huge relationship between's PASI score and Disease length or Age.

On the repudiate an examination by Hägg et al. [19] which showed that the lower PASI score in ladies is predictable and isn't a consequence of chance varieties. In a multivariable direct relapse, controlling for a few different variables, this distinction remained genuinely critical. The distinction taking all things together yet one of the unmistakable components of the PASI score was likewise huge, both in unadjusted examinations of medians and in the ordinal calculated relapse models changed by age, BMI, infection term, associative PsA, smoking status, and season. Be that as it may, concerning the head, ladies' and men's PASI scores were equivalent.

Additionally In an elucidating concentrate from Ireland, it was seen that twice as numerous men $(n=93)$ got fundamental treatment contrasted and ladies $(n=53)$ [p $=0.015]$, and that ladies had less serious psoriasis (experienced by the clinicians) contrasted and men(20).

In a review concentrate from Japan, Sakai et al. (21)explored the prognostic elements for the drawn out result of plaque psoriasis patients (109 men and 60 ladies) in a strategic relapse, and found that men grew more serious psoriasis as indicated by the Dermatology Index of Disease Severity during follow-up contrasted and ladies $(\mathrm{p}=0.046)$, in the wake of adapting to age and BMI.

In our investigation we exhibited that there wass high critical relationship between's Netrin1and degree, additionally there is huge connection between's Netrin1and Disease length while there is no huge connection between's Netrin 1 and Age.

Demir et al. (15) established that psoriasis patients had netrin-1 levels was adversely associated with BMI, serum CRP levels, sickness term and PASI.

The overall non huge example size was a restricting variable, another restricting element was the absence of follow up after treatment of the examined cases to survey level in netrin-1 after treatment.

Taking everything into account, we assessed netrin-1 levels and their relationship with term and seriousness of infection in psoriasis patients in this investigation. We established that netrin-1 diminished in psoriasis patients.. Moreover, psoriasis patients were exhibited to have a huge negative connection among netrin-1 levels, infection span and PASI. Diminished netrin-1 levels may assume a part in the pathogenesis of ongoing irritation in psoriasis patients. In any case, these discoveries ought to be deciphered cautiously as the force of this examination is restricted by its generally little partner and absence of imminent information. Further examinations are required.

\section{Conclusion}

Netrin 1 levels play a role in the inflammation of psoriasis and its role in metabolic diseases associated with this disease. Netrin1 can be used as indicator of disease degree and disease duration.

\section{References}

[1] Sk.Kurd , JM.Gelfand. The prevalence of previously diagnosed and undiagnosed psoriasis in US adults: results from NHANES 2003-2004. J Am Acad Dermatol.vol.60,pp. 218-224. ,2009.

[2] K.Danielsen, AO.Olsen, T.Wilsgaard and AS.Furberg Is the prevalence of psoriasis increasing? A 30-year follow-up of a populationbased cohort.Br J Dermatol.vol.168,pp.1303$10,2013$.

[3] A.Menter, A.Gottlieb, SR.Feldman. Guidelines of care for the management of psoriasis and psoriatic arthritis: section 1.Overview of psoriasis and guidelines of care for the treatment of psoriaisis with biologics.vol.8,pp.785-963,2008.

[4] D.Pariser, B.Schenkel, C.Carter, K.Farahi, TM.Brown, CN.Ellis and Psoriasis Patient Interview Study Group A multicenter, non-interventional study to evaluate patient-reported experiences of living with psoriasis. J Dermatol Treat.vol.8,pp. 1-8,2015.

[5] M.Augustin, MA.Radtke, G.Glaeske, K.Reich, E.Christophers, I.Schaefer. Epidemiology and Comorbidity in Children with Psoriasis and Atopic Eczema. Dermatology.vol. 231(1),pp.35-40,2015.

[6] JL.Harden, JG.Krueger and AM.Bowcock. The immunogenetics of psoriasis: a comprehensive review. J Autoimmun.vol. 64,pp.66-73,2015.

[7] WH.Boehncke, MP.Schön. Psoriasis.Lancet Lond Engl.vol.386(9997),pp.983-994. doi: 10.1016/S01406736(14)61909-7,2015.

[8] Serafini Tito, Kennedy, E.Timothy, Galko, J.Michael, Mirzayan, Christine, Jessell, M. Thomas and Tessier-Lavigne. The netrins define a family of axon outgrowth-promoting proteins homologous to C. Elegans UNC6.Cell.vol. 78(3),pp. 409-24,1994.

[9] JA.Meyerhardt, K.Caca, BC. IEckstrand, G.Hu, C.Lengauer, S.Banavali, AT.Look and ER.Fearon Netrin-1: interaction with deleted in colorectal cancer 
(DCC) and alterations in brain tumors and neuroblastomas.Cell Growth Differ.vol. 10 (1),pp.35-42,1999.

[10] JM.Rosenberger, V.Schwab, Mirakaj . Hypoxiainducible factor-dependent induction of netrin-1 dampens inflammation caused by hypoxia," Nature Immunology, vol.10, pp. 195-202,2009.

[11]PC.VandeKerkhof, J.Schalkwijk, Psoriasis. In: Bolognia JL, Jorizzo JL, Rapini RP, Dermatology. 2nd ed. Spain Mosby.vol.5,pp.115-48,2008.

[12] J.Yim, G.Kim, BW.Lee, ES.Kang, BS.Cha, JH.Kim and YH.Lee. Relationship between circulating netrin1 concentration, impaired fasting glucose, and newly diagnosed type 2 diabetes. Frontiers in endocrinology.vol.9,pp. 691,2018.

[13] M.M.Tollefson, CS.Crowson, MT.McEvoy, H.Maradit Kremers. Incidence of psoriasis in children: A population-based study.J Am Acad Dermatol.vol. 62,pp.979-987,2010.

[14]D.Solmaz, S.Bakirci, G.Kimyon, E.Gunal, A.Dogru, O.Bayindir and G.Cetin. Impact of Having Family History of Psoriasis or Psoriatic Arthritis on Psoriatic Disease. Arthritis care \& research.vol.72(1),pp. 6368,2020.

[15] PS.Demir, ET.Gokdogan, CS.Karakas. Evaluation of Serum Netrin-1 Levels in Psoriasis Patients. Clin Dermatol J .vol. 4(6).pp. 000197,2019.
[16] JG.Krueger, A.Bowcock. Psoriasis pathophysiology: Current concepts of pathogenesis. Ann Rheum Dis.vol.64 Suppl ,pp.2:ii30-6,2005.

[17] BD.Wilson, M.Ii, KW.Park, A.Suli, LK.Sorensen, F.Larrieu-Lahargue. Netrins promote developmental and therapeutic angiogenesis. Science.vol.313,pp.640-4,2006.

[18] X.Lu, Le F.Noble, L.Yuan , Q.Jiang, B.De Lafarge, Sugiyama, M. Autiero. The netrin receptor UNC5B mediates guidance events controlling morphogenesis of the vascular system. Nature.vol. 432(7014),pp. 179-186,2004.

[19]D.Hägg, A.Sundström, M.Eriksson, \& M.SchmittEgenolf. Severity of psoriasis differs between men and women: a study of the clinical outcome measure psoriasis area and severity index (PASI) in 5438 Swedish register patients. American Journal of Clinical Dermatology.vol.18(4),pp. 583-590,2017.

[20]D.White, SJ.O'Shea and S.Rogers. Do men have more severe psoriasis than women?.Journal of the European Academy of Dermatology and Venereology: JEADV.vol. 26(1), pp.126-127. ,2011,

[21]R.Sakai, S.Matsui, M.Fukushima, H.Yasuda, H.Miyauchi, and Y.Miyachi. Prognostic factor analysis for plaque psoriasis. Dermatology.vol.211(2),pp. 103-106,2005. 